\title{
Optimisation of hospital resource use: A rapid review of the literature
}

\author{
Dominic Madell, Luis Villa, Brooke Hayward, Lyndsay Le Comte \\ Ko Awatea, Counties Manukau District Health Board, New Zealand
}

Received: November 10, 2015

Accepted: December 4, 2015

Online Published: December 8, 2015

DOI: $10.5430 /$ jha.v5n1p107

URL: http://dx.doi.org/10.5430/jha.v5n1p107

\begin{abstract}
Project System Wide Integration for Transformation (SWIFT) is a programme of work supported by developments in technology that aims to improve the health of people in Counties Manukau through initiatives focused on community-based care and improving hospital systems. A "rapid review" of literature focussing optimisation of resource use in hospitals was carried out to support this programme. In total, 36 articles were considered in detail for inclusion in this rapid review, with many other articles considered briefly from title or abstract alone. Of the 36 articles, 24 (66.7\%) were ultimately deemed relevant, and included. The review found reasonable evidence that patient length of stay can be reduced by using: (1) collaborative physician/nurse multidisciplinary care management of medical patients with expedited discharge, and assessment following discharge; (2) perioperative anaesthetic and pain management strategies for primary total hip (THA) and total knee arthroplasty (TKA); (3) the use of specialist nurses across a variety of roles, and team midwives who provide care for pregnant women from the beginning of care to the end of the post-natal period. It also found that there is potential for a reduction in adverse cardiac outcomes in hospitals through: (1) prescribing guideline discharge therapies in acute cardiac care, and (2) remote management of heart failure patients implanted with cardioverter defibrillators. The review also suggested that appointment cancellations or instances of non-attendance can be reduced by: (1) the establishment of pre-operative assessment and consultation clinics; (2) distributed access to scheduling systems; (3) preferentially loading appointments onto high-attendance days; and (4) the use of text messaging or automated phone calls to remind patients about appointments.
\end{abstract}

Key Words: Resources, Efficiency, Improvement, Hospital, Optimisation

\section{INTRODUCTION}

Project System Wide Integration for Transformation (SWIFT) is a programme of work supported by developments in technology, that aims to improve the health of people in Counties Manukau through initiatives focused on community-based care and improving hospital systems. ${ }^{[1]}$ It is being carried out by the Counties Manukau District Health Board (DHB) in New Zealand over a four-year period. Counties Manukau DHB has a population that is younger than the national average. It has a slightly higher proportion of $\mathrm{M} \bar{a}$ ori (16.3\% vs. $15.4 \%$ ), a much higher proportion of
Pacific people (23.2\% vs. $6.7 \%)$, and more people in the most deprived section of the population (Ministry of Health, 2015). A literature review was carried out to contribute to an aim of Project SWIFT that was to optimise the use of resources in hospitals. These objectives required a review of New Zealand and international research literature to be carried out.

\section{METHODS}

A rapid review methodology was used for this literature review. This is a streamlined literature review process that

\footnotetext{
*Correspondence: Dominic Madell; Email: dominic.madell@middlemore.co.nz; Address: Ko Awatea Research and Evaluation Office, Level 1 Esmé Green Building, Middlemore Hospital, 100 Hospital Road, Otahuhu, Private Bag 93311, Auckland 1640, New Zealand.
} 
may be shortened by, for example, limiting the number of databases searched, the types of study design included, the languages that articles are written in, the dates when articles were written, and the level of inclusion of "grey" literature. Also, the number of reviewers involved in decisions about inclusion and exclusion of articles, data extraction and quality assessment may be fewer than normal. ${ }^{[2]}$ Because of this streamlined procedure, the limitations of rapid review can include selection bias, publication bias and language of publication bias. However, the methodology was viewed as appropriate for this review due to the limited time and resources available, and it provided a good balance between costs and benefits.

The methodology consisted of identifying and selecting publications that were relevant to the area of focus, critically appraising publications, analysing the data reported, and describing results. First, inclusion and exclusion criteria were defined to guide which studies to include in the literature review. Articles included were those that reported research relating to reduction in length of stay; reduction in hospital staff downtime; reduction in appointment cancellations; and efficient use of the hospital building.

Any research with a publication date from 2005 to 2015 that was written in English, and with any study design, was included. Excluded studies included those relating to: services based in the community; improvements gained from staff learning new clinical or technical skills; non-peer-reviewed studies that were carried out outside of New Zealand; nonresearch articles; and articles reporting process or simulation models, or methods of analysis development, where the model or methods developed were not then applied to a real-life setting.

Several search engines (Medline Complete, Ebsco Health Business Elite, Cochrane, Health Foundation Research Scan, Heath Improvement and Innovation Resource Centre portal, Google Scholar, Pub Med, Science Direct, Web of Knowledge) were used to search for articles using combinations of the following terms: "scheduling", "hospital", "reduction", "length of stay", "bed days", "appointment", "staff", "cancellation", "building", "scheduling", "resources", "equipment", and "efficiency".

Titles or abstracts of papers found were checked and nonrelevant literature was removed, with five percent of nonrelevant articles being audited by a second reviewer to check for agreement. As articles were read, further references were also sought from any relevant papers found using a snowballing technique.

The papers included were then critically reviewed by provid- ing a written summary of methods, findings and conclusions from each of the articles, and summarising the limitations of the research in terms of their applicability to the hospital context. The quality of evidence in each article was scored on a number of variables relevant to the project: study design, participant characteristics, health system in which the research was carried out, and population. Variables were scored from zero to three. Study design and health system were then rated by a factor of two, as these were considered the most important variables for the review. The scoring system resulted in a total score out of 18 for each article, where 0-6 was defined as weak evidence, 7-15 as moderate evidence, and 16-18 as strong evidence.

For study design, three points were awarded to systematic reviews that included at least one randomised controlled trial (RCT), or research or evaluation studies with experimental designs that included randomisation; two points were awarded to systematic reviews that did not include RCTs, prospective cohort studies, or evaluations with an experimental design but without randomisation; one point was awarded to retrospective cohort studies, case-control studies or evaluations with before/after designs, or that described baseline data; and no points were awarded to cross sectional surveys, evaluations without comparison groups and qualitative research.

The participant characteristics category was rated according to the type of participants reported in the article. Articles that featured participants who were hospital staff from a range of clinical disciplines and that featured patient perspectives were awarded three points, while two points were awarded to articles which featured participants that were staff from a range of clinical disciplines only. One point was awarded to articles which featured staff participants from a single clinical discipline, and studies which did not define their participants were awarded zero points.

If the article featured patients only as participants, then more points were awarded to studies featuring patients that had most relevance to the types of patient at Counties Manukau DHB. So, three points were awarded if an article contained participants that were multicultural or multiethnic, and from medium to low socioeconomic urban areas. Two points were awarded if participants were from low socioeconomic urban areas only. One point was awarded if participants were from medium-high socioeconomic areas, or if ethnic or cultural diversity was not specified. Finally, zero points were awarded if there was no description of participants, if they were from a high income population, if they received care from private facilities, or if they received care from a facility in the developing world. 
For the health system category, studies which reported research that was carried out in settings most similar to those found in New Zealand were awarded higher scores. Therefore, three points were awarded to studies carried out in public hospitals, two points were awarded to studies that were carried out in hospitals that were publicly funded but privately run, and zero points were awarded to studies carried out in private hospitals, or where there was no description of the setting (there was no one point score available for this category).

For the population category, three points were awarded to studies that demonstrated an impact across an entire hospital, two points were awarded to studies that demonstrated an impact across a number of healthcare domains within a hospital, one point was awarded to studies that demonstrated an impact in a single healthcare domain within a hospital, and no points were awarded to studies that poorly defined the type of healthcare domain in which the research had occurred.

Scores were interpreted cautiously, and were mainly used as a way of presenting the strength of the evidence in an easy-to-read format. A further audit of the scores from $10 \%$ of the included articles was carried out by a second reviewer, to check for agreement.

\section{RESUltS}

In total, 36 articles were read in full to assess their relevance for inclusion in this review, with many other studies being considered briefly from title or abstract alone. Of these 36 articles, 24 (66.7\%) were judged relevant and included. Of the 24 studies, six were systematic literature reviews, three were RCTs or quasi-experimental but involving randomisation, nine had pre-post designs or compared with baseline data, one was a prospective cohort study, two were retrospective observational studies, one was a "narrative" literature review (where results were not quantified nor study design considered), and two were descriptive studies without comparison groups.

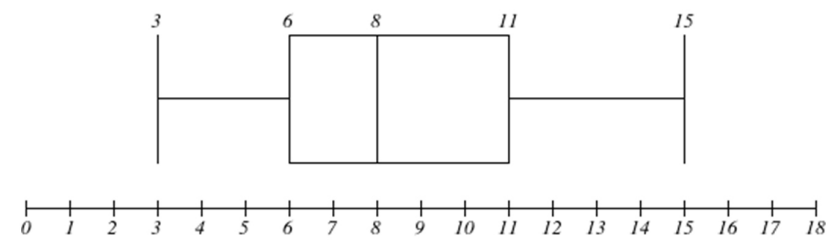

Figure 1. Flow chart of search results of studies from searching and screening

Studies were carried out in a diverse range of international hospitals in Australia, the Netherlands, UK, USA, Canada,
Ireland, Scotland, Norway, Trinidad, Denmark and Iran. The average score out of 18 for these articles was eight, and the range of scores is illustrated in the box plot in Figure 1.

A summary of the articles is included in Table 1 below.

A number of articles suggested strategies for reducing patient length of stay: ${ }^{[3-5]}$

\subsection{Collaborative physician/nurse practitioner multidis- ciplinary care management}

Cowan et al. ${ }^{[3]}$ suggested that there is potential for using collaborative physician/nurse practitioner multidisciplinary care management of patients alongside team-based planning, with assessment after expedited discharge. Their study compared two groups of general medicine patients with 581 patients in the experimental group and 626 patients in the control group. The experimental group received care through a daily multidisciplinary round, as well as from an advanced practice nurse during hospitalisation and for a month after discharge, and from a hospitalist medical director and another hospitalist, while the control group received usual care. Both the means and medians indicated that the experimental group stayed a day less in the hospital than the control group (3 vs. 4 days, $p<.0001$ ), and there were no significant group differences in mortality or readmissions.

\subsection{Perioperative anaesthetic and pain management strategies for primary total hip (THA) and total knee arthroplasty (TKA)}

Literature also suggested that patient length of stay could be reduced by perioperative anaesthetic and pain management strategies for THA and TKA. Peters et al. ${ }^{[4]}$ compared two cohorts of 50 consecutive THA and 50 TKA patients before and after initiation of new strategies that used regional rather than general anaesthesia, avoided intravenous narcotics, provided scheduled oral medications, and carried out physical therapy beginning on the day of surgery. The authors found that for TKA patients, length of stay reduced from an average of 3.1 to 2.5 days ( $p=.002$ ) while THA patients' length of stay reduced from an average of 3.7 days to 2.5 days ( $p=.000005)$ after initiation of the strategies. However, which of the strategies were the most important contributors to the results was not identified.

\subsection{Use of specialist nurses and team midwives}

The review also found that patient length of stay could be reduced by the use of specialist nurses and team midwives who provide care for pregnant women from the beginning of care to the end of the post-natal period. In a systematic review, Butler et al. ${ }^{[5]}$ suggested that that the addition of spe- 
cialist nurses to nursing staff across a variety of roles resulted in shorter patient hospital stays (RR: $-1.35,95 \%$ CI -1.92 to $0.78 ; \mathrm{Z}=4.61, p<.00001$ ). The authors also described an impact of introducing team midwifery (where the same midwife provides care from the beginning of a woman's care to the end of the post-natal period) resulting in shorter length of stay in hospital (RR $-0.30,95 \%$ CI $-0.54,-0.06 ; \mathrm{Z}=2.41$, $p=.02)$ and in special care nursery (SCN) (RR -2.00, 95\% CI $-2.07,-1.93 ; Z=5.946, p<.00001)$.

Table 1. Summary of the main findings from each paper included in literature review

\begin{tabular}{|c|c|c|c|}
\hline Article & Strategy used & Main result & $\begin{array}{l}\text { Score out of } \\
18 \text { awarded }\end{array}$ \\
\hline Cowan et al. ${ }^{[3]}$ & $\begin{array}{l}\text { Collaborative physician/nurse practitioner multidisciplinary care management of } \\
\text { general medicine patients alongside team-based planning, with assessment after } \\
\text { expedited discharge }\end{array}$ & \multirow{3}{*}{$\begin{array}{l}\text { Reduced patient length of } \\
\text { stay }\end{array}$} & 8 \\
\hline Peters et al. ${ }^{[4]}$ & $\begin{array}{l}\text { Perioperative anaesthetic and pain management strategies for primary total hip } \\
\text { (THA) and total knee arthroplasty (TKA) }\end{array}$ & & 3 \\
\hline Butler et al. ${ }^{[5]}$ & $\begin{array}{l}\text { Use of specialist nurses and "team" midwives who provide care for pregnant } \\
\text { women from the beginning of care to the end of the post-natal period }\end{array}$ & & 15 \\
\hline Astley et al. ${ }^{[6]}$ & $\begin{array}{l}\text { Clinicians reminded to prescribe guideline discharge therapies in acute cardiac } \\
\text { care, and adequate levels of cardiac care staff to patient ratios }\end{array}$ & \multirow{2}{*}{$\begin{array}{l}\text { Reduction in adverse } \\
\text { outcomes }\end{array}$} & 10 \\
\hline Landolina et al. ${ }^{[7]}$ & $\begin{array}{l}\text { Remote management of heart failure patients with implanted cardioverter } \\
\text { defibrillators (ICDs) }\end{array}$ & & 10 \\
\hline Knox et al. ${ }^{[8]}$ & \multirow{3}{*}{$\begin{array}{l}\text { Establishment of pre-operative assessment and consultation clinics } \\
\text { Redesign of a pathway for elective surgery, including improved communication } \\
\text { and management systems, a new day-surgery centre, earlier assessment of } \\
\text { patients, and increased involvement of patients in the scheduling of surgeries }\end{array}$} & \multirow{3}{*}{$\begin{array}{l}\text { Reduction in cancellations } \\
\text { of operations }\end{array}$} & 11 \\
\hline Farasatkish et al. ${ }^{[9]}$ & & & 3 \\
\hline Holvid et al. ${ }^{[10]}$ & & & 13 \\
\hline Dexter et al. ${ }^{[16]}$ & Distributed access to timetabling systems & $\begin{array}{l}\text { Increase in anaesthetics } \\
\text { performed in allocated time }\end{array}$ & 7 \\
\hline Hasvold \& Wootton ${ }^{[11]}$ & \multirow{3}{*}{ Use of text messaging or automated phone call reminders to patients } & \multirow{3}{*}{$\begin{array}{l}\text { Reduction in appointment } \\
\text { cancellations }\end{array}$} & 13 \\
\hline Taylor et al. ${ }^{[12]}$ & & & 14 \\
\hline Downer et al. ${ }^{[13]}$ & & & 21 \\
\hline $\begin{array}{l}\text { LaGanga }^{[14]} \\
\text { Ellis \& Jenkins }\end{array}$ & Preferentially loading appointments onto more popular day-time slots & Increased patient attendance & 6 \\
\hline Ryckman et al. ${ }^{[17]}$ & & & 7 \\
\hline Dubois \& Singh ${ }^{[20]}$ & \multirow[b]{2}{*}{ (1) did not report quantifiable results or the statistical significance of their findings } & & 4 \\
\hline Moffatt \& Eley ${ }^{[21]}$ & & & 6 \\
\hline Nancarrow et al. ${ }^{[22]}$ & \multirow[t]{2}{*}{ (2) design limitations such as lack of randomisation or biased samples } & & 6 \\
\hline Koshy et al. ${ }^{[23]}$ & & & 9 \\
\hline Hariharan et al. ${ }^{[24]}$ & \multirow[t]{3}{*}{ (3) a lack of detail about methodologies used to obtain findings } & & 6 \\
\hline Thiel et al. ${ }^{[25]}$ & & & 8 \\
\hline Leggat et al. ${ }^{[26]}$ & & & 11 \\
\hline
\end{tabular}

3.4 Clinicians reminded to prescribe guideline discharge therapies in acute cardiac care, and adequate levels of cardiac care staff to patient ratios

Other articles suggested how the incidence of adverse outcomes in hospitals could be reduced, which one would expect to lead to more optimal use of resources. ${ }^{[6,7]}$ In an "Acute Coronary Syndrome Prospective Audit", Astley et $a l .{ }^{[6]}$ found rates of adverse cardiac outcomes among Aus- tralian hospitals were lower in hospitals where clinicians were reminded to prescribe guideline discharge therapies in acute cardiac care, and where there were adequate levels of cardiac care staff to patient ratios $(p<.05)$.

\subsection{Remote management of heart failure patients with implanted cardioverter defibrillators (ICDs)}

Landolina et al. ${ }^{[7]}$ also suggested that reductions in adverse outcomes among cardiac patients could be achieved by re- 
mote management of heart failure patients with ICDs. In a prospective multicentre randomized trial with 200 patients, Landolina et al. found that remote monitoring reduced the number of healthcare visits for patients, as compared with standard management (4.40 vs. 5.74 events per year; $p=$ $.001)$. In addition, the time from an ICD alert to review of the data was reduced from 24.8 days to 1.4 days $(p=.001)$.

\subsection{Establishment of pre-operative assessment and con- sultation clinics}

The literature review also found that there is potential for reduction in cancellations of surgery or operations through the establishment of pre-operative assessment and consultation clinics, which allow time for further testing and medical evaluation of patients and increased involvement of patients in the scheduling of surgeries. Knox et al. ${ }^{[8]}$ carried out a retrospective review of all surgical cases over a one year period prior to and one year after the establishment of a pre-operative assessment clinic, and found that pre-assessment resulted in a significant reduction in case cancellations (114 vs. 256, $p<.001)$. Similarly, Farasatkish et al ${ }^{[9]}$ prospectively studied the cancellation rates for 866 patients scheduled for an operation before establishment of a pre-anaesthesia consultation clinic in a teaching hospital, and 850 cases that were scheduled for after. The cancellation rate in the first group was $146 / 866(16.8 \%)$ but in the second group was only $113 / 850(13.29 \%)(p=.046)$.

\subsection{Redesign of pathway for elective surgery}

Holvid et al. ${ }^{[10]}$ carried out a pre-post study over five years that looked at the redesign of a pathway for elective surgery in a Norwegian hospital, involving all surgical departments. As well as improved communication and management systems, and a new day-surgery centre, the changes included earlier assessment of patients, and increased involvement of patients in the scheduling of surgeries. The mean cancellation rate was reduced from $8.5 \%$ to $4.9 \%$ (95\% CI for mean reduction $2.6-4.5, p<.001)$.

\subsection{Reminders to patients and loading appointments onto popular day-time slots}

Other articles suggested that the use of text messaging or automated phone call reminders to patients can significantly reduce appointment cancellations, ${ }^{[11-13]}$ while still others suggested that preferentially loading appointments onto more popular day-time slots can better increase the likelihood of patient attendance. ${ }^{[14,15]}$ Another finding from the literature review was that distributed access to timetabling systems can increase efficiency. For example, Dexter et al. ${ }^{[16]}$ carried out an observational study of an intervention where an anaesthesia department gave staff in other departments permission

Published by Sciedu Press to schedule non-operating room anaesthesia teams through distributed access to their time management system. A key finding was that anaesthetics performed in allocated time increased progressively from $0 \%$ to $75 \%(p<.00001)$.

\subsection{Studies of limited value}

The findings from other articles considered by this review were of limited value to our context, because they had one or more of the following issues: (1) they did not report quantifiable results or the statistical significance of their findings; (2) they had design limitations such as lack of randomisation or biased samples; or (3) they had a lack of detail about methodologies used to obtain findings. ${ }^{[17-26]}$

\section{Discussion}

The priority of this review was to find articles that reported either a high quality of evidence or summarised a large quantity of evidence. However, it is acknowledged that not all articles of relevance may have been identified due to the rapid review methodology employed. Nevertheless, this literature review found that there is potential for reducing patient length of stay by using: (1) collaborative physician/nurse practitioner multidisciplinary care management of patients alongside team-based planning, with assessment after expedited discharge; (2) perioperative anaesthetic and pain management strategies for THA and TKA; (3) specialist staff such as specialist nurses and team midwives who provide care for pregnant women from the beginning of care to the end of the post-natal period. It also found that there is potential for a reduction in adverse outcomes in hospitals through: (1) prescribing guideline discharge therapies in acute cardiac care; and (2) remote management of heart failure patients implanted with cardioverter defibrillators.

Furthermore the review suggested that numbers of appointment cancellations can be reduced by: (1) the establishment of pre-operative assessment and consultation clinics, to allow time for further testing and medical evaluation of patients, alongside (2) increased involvement of patients in the scheduling of surgeries. Finally, the review suggested that distributed access to scheduling systems, and preferentially loading appointments onto high-attendance days can increase the efficiency of hospital scheduling, while the use of text messaging or automated phone calls to remind patients about appointments can also make them more likely to attend.

While other measures that contribute to optimal use of hospital resources may also exist, this review suggested that the evidence for those interventions reported was strongest, as they had direct effects on either patient length of stay, reductions in adverse outcomes, or reductions in appointment cancellations. 


\section{Conclusion}

The findings from this literature review will be considered in context alongside many other initiatives that contribute to Project SWIFT, such as quality improvement investigations, evaluations of systems and services, engagement with patients, and improvements to IT systems. This literature review will contribute to the project's "detailed design" phase, which involves developing the overall SWIFT program of work: the phase ends with the presentation of a number of business cases for change to the Counties Manukau DHB.

\section{REFERENCES}

[1] Project SWIFT [Internet]. New Zealand, Counties Manukau Health [cited 2015 Jul 7]. Available from: http: //www. countiesmanukau .health.nz/assets/About-CMH/P rojects/SWIFT/CMDHB-About-Swift-2015.03-V5-LR.pdf

[2] Methods: Synthesis 1. Rapid reviews: Methods and implications. National Collaborating Centre for Methods and Tools [Internet] Canada, Ontario, Hamilton [cited 2015 Jul 7]. Available from: http://www.nccmt.ca/pubs/Methods_Synthesis1.pdf

[3] Cowan MJ, Shapiro M, Hays RD, et al. The Effect of a Multidisciplinary Hospitalist/Physician and Advanced Practice Nurse Collaboration on Hospital Costs. Journal of Nursing Administration. 2006; 36(2): 79-85. PMid: 16528149. http://dx.doi.org/10.1097/0 0005110-200602000-00006

[4] Peters CL, Shirley B, Erickson J. The Effect of a New Multimodal Perioperative Anesthetic Regimen on Postoperative Pain, Side Effects, Rehabilitation, and Length of Hospital Stay After Total Joint Arthroplasty. 2006; 21(6): 132-138.

[5] Butler M, Collins R, Drennan J, et al. Hospital nurse staffing models and patient and staff-related outcomes. Cochrane Database of Systematic Reviews. 2011; 6(7): CD007019. http://dx.doi.org/1 0.1002/14651858.cd007019.pub2

[6] Astley CM, MacDougall CJ, Davidson PM, et al. Lost in Translation Health Resource Variability in the Achievement of Optimal Performance and Clinical Outcome. Circulation: Cardiovascular Quality and Outcomes. 2011; 4(5): 512-520. http://dx.doi .org/10.11 61/circoutcomes.110.960229

[7] Landolina M, Perego GB, Lunati M, et al. Remote Monitoring Reduces Healthcare Use and Improves Quality of Care in Heart Failure Patients With Implantable Defibrillators. Circulation. 2012; 125 2985-2992. PMid: 22626743. http://dx.doi.org/10.1161/C IRCULATIONAHA. 111.088971

[8] Knox M, Myers E, Wilson I, et al. The impact of pre-operative assessment clinics on elective surgical case cancellations. Surgeon. 2009; 7(2): 76-78. http://dx.doi.org/10.1016/S1479-666X (09)8 0019-X

[9] Farasatkish R, Aghdaii N, Azarfarin R, et al. Can preoperative anesthesia consultation clinic help to reduce operating room cancellation rate of cardiac surgery on the day of surgery? Middle East Journal of Anesthesiology. 2009; 20(1): 93-96. PMid: 19266833.

[10] Holvid E, Bukve O, Haug K, et al. A new pathway for elective surgery to reduce cancellation rates. BMC Health Services Research. 2012; 12: 154. PMid: 22686475. http://dx.doi.org/10.1186 /1472-6963-12-154

[11] Hasvold PE, Wootton R. Use of telephone and SMS reminders to improve attendance at hospital appointments: a systematic review. Journal of Telemedicine and Telecare. 2011; 17: 358-364. PMid: 21933898. http://dx.doi.org/10.1258/jtt.2011.110707

[12] Taylor NF, Bottrell J, Lawler K, et al. Mobile Telephone Short Message Service Reminders Can Reduce Nonattendance in Physical Therapy Outpatient Clinics: A Randomized Controlled Trial.
Arch Phys Med Rehabil. 2012; 93: 21-26. PMid: 22000821. http: //dx.doi.org/10.1016/j.apmr.2011.08.007

[13] Downer SR, Meara JG, Da Costa AC. Use of SMS text messaging to improve outpatient attendance. MJA. 2005; 7: 366-368.

[14] LaGanga LR. Lean service operations: reflections and new directions for capacity expansion in outpatient clinics. Journal of Operations Management. 2011; 29(5): 422-433. http://dx.doi.org/10.10 $16 / j \cdot$ jom. 2010.12.005

[15] Ellis DA, Jenkins R. Weekday Affects Attendance Rate for Medical Appointments: Large-Scale Data Analysis and Implications. Plos One. 2012. Available from: http://journals.plos.org/plos one/article?id=10.1371/journal . pone. 0051365

[16] Dexter F, Xiao Y, Dow AJ, et al. Coordination of Appointments for Anesthesia Care Outside of Operating Rooms Using an EnterpriseWide Scheduling System. Anaesthesia \& Analgesia. 2007; 105(6): 1701-1710. PMid: 18042870. http://dx.doi.org/10.1213/01. ane.0000287686.23187.3f

[17] Ryckman, Elena Adler, Amy M Anneken, et al. Cincinnati Children's Hospital Medical Center: Redesigning Perioperative Flow Using Operations Management Tools to Improve Access and Safety. 2006. Available from: http://www.ihoptimize.org/knowled ge-center-case-studies.htm

[18] Breen P, Murphy K, Browne G, et al. Formative evaluation of a telemedicine model for delivering clinical neurophysiology services part I: utility, technical performance and service provider perspective. Bmc Medical Informatics \& Decision Making. 2010; 10(21): 2260-2268. http://dx. doi . org/10.1186/1472-6947-10-48

[19] Hersh WR, Hickam DH, Severance SM, et al. Diagnosis, access and outcomes: update of a systematic review of telemedicine services. Journal of Telemedicine \& Telecare. 2006; 12(1): 3-31. PMid: 16989671. http://dx.doi.org/10.1258/13576330677 8393117

[20] Dubois CA, Singh D. From staff-mix to skill-mix and beyond: towards a systemic approach to health workforce management. Human Resource Health. 2009; 7(1): 87. PMid: 20021682. http: //dx.doi.org/10.1186/1478-4491-7-87

[21] Moffatt JJ, Eley DS. The reported benefits of telehealth for rural Australians. Australian Health Review. 2010; 34: 276-281. PMid: 20797357. http://dx.doi.org/10.1071/AH09794

[22] Nancarrow SA, Roots A, Grace S, et al. Implementing large-scale workforce change: learning from 55 pilot sites of allied health workforce redesign in Queensland, Australia. Human resources for health. 2013; 11(1): 66. PMid: 24330616. http://dx.doi.org/10.1186 /1478-4491-11-66

[23] Koshy E, Car J, Majeed A. Effectiveness of mobile-phone short message service (SMS) reminders for ophthalmology outpatient appointments: Observational study. BMC Ophthalmology. 2008; 8: 9. PMid: 18513438. http://dx.doi .org/10.1186/1471-2415-8-9

[24] Hariharan S, Chen D, Merritt-Charles L. Evaluation of the utilization of the preanaesthetic clinics in a University teaching hospital 
BMC Health Services Research. 2006; 6: 59. PMid: 16719913. http://dx.doi.org/10.1186/1472-6963-6-59

[25] Thiel CL, Needy KL, Ries R, et al. Building design and performance: A comparative longitudinal assessment of a Children's hospital. Building and Environment. 2014; 78: 130-136. http: //dx.doi.org/10.1016/j. buildenv. 2014.04.001
[26] Leggat SG, Bartram T, Stanton P, et al. Have process redesign methods, such as Lean, been successful in changing care delivery in hospitals? A systematic review. Public Money \& Management. 2015; 35(2): 161-168. http://dx.doi.org/10.1080/0954096 2.2015 .1007714 